\title{
Pengembangan Algoritma untuk Penyempurnaan Gerakan dan Kestabilan Robot Humanoid berbasis Kondo KHR - 3HV
}

\author{
Daniel Santoso ${ }^{1}$, Deddy Susilo², Yonas Aditya Darmawan ${ }^{3}$ \\ Program Studi Teknik Elektro, \\ Fakultas Teknik Elektronika dan Komputer, \\ Universitas Kristen Satya Wacana, Salatiga \\ 1daniel.santoso@staff.uksw.edu, 2deddy.susilo@staff.uksw.edu, \\ 3612009034@student.uksw.edu
}

\begin{abstract}
Ringkasan
Meskipun R2C telah meraih juara dua tingkat nasional dalam KRSBI 2013 (Kontes Robot Sepak Bola Indonesia 2013), robot humanoid yang dimiliki oleh R2C masih memiliki kekurangan dalam sistem kontrol dan motion (gerakan). Sistem kontrol pada robot dibagi menjadi 2 bagian utama, yaitu kontrol aktuator robot dan kontrol utama. Kontrol aktuator robot dalam hal ini adalah servo controller untuk mengontrol sistem gerak robot yang keseluruhannya terdiri dari motor servo, dimana servo controller mendapat perintah gerakan yang sudah didefinisikan di kontrol utama. Sedangkan kontrol utama bertugas untuk mensinkronisasi antara gerak robot dengan perintah yang telah diolah oleh mikrokontroler sehingga nantinya robot dapat melakukan tugas-tugas sesuai dengan perintah yang dikirim dari smartphone. Pengujian dilakukan dengan membandingkan algoritma lama yang dipakai robot saat mengikuti KRSBI 2013 dengan algoritma baru yang dibuat oleh penulis. Persentase keberhasilan robot ketika bergerak tetap stabil saat robot melakukan pergantian gerakan tanpa adanya delay dari program pada algoritma lama hanya mencapai $41 \%$ sedangkan pada algoritma baru persentase keberhasilan dapat mencapai $95 \%$.
\end{abstract}

Kata kunci: Algoritma kontrol, Kondo KHR-3HV, Humanoid Robot Soccer, motion cut

\section{Pendahuluan}

Meskipun tim Robotic Research Centre (R2C) Universitas Kristen Satya Wacana (UKSW) telah pernah meraih juara dua tingkat nasional Kontes Robot Sepak Bola Indonesia (KRSBI) pada tahun 2013, robot humanoid yang dimiliki oleh R2C masih memiliki kekurangan dalam sistem kontrol dan gerakan. Ketika robot diperintah untuk bergerak maju kemudian langsung diperintah untuk bergeser ke kanan, pergantian dari gerakan maju ke gerakan geser kanan masih sangat lambat dan persentase keberhasilan robot ketika berada dalam fase peralihan antara gerakan satu menuju gerakan lainnya hanya mencapai $50 \%$. Untuk dapat bersaing dengan tim robot dari perguruan tinggi lainnya pada KRSBI yang akan datang sangat diperlukan gerakan robot yang cepat dan tingkat keberhasilan eksekusi gerakan tinggi sehingga robot dapat seimbang dan dengan cepat menguasai bola.

Berdasarkan permasalahan di atas, pada penelitian ini dikembangkan sebuah algoritma untuk penyempurnaan gerakan dan kestabilan pada robot humanoid R2C 
UKSW. Diharapkan algoritma pengendalian gerakan robot yang telah diperbaiki dapat membuat robot humanoid R2C UKSW menjadi lebih kompetitif pada KRSBI mendatang.

\section{Kajian Pustaka}

Beberapa robot dengan tujuan sejenis telah dikembangkan dengan menggunakan berbagai macam algoritma pengendali. Pada bab ini akan dibahas beberapa di antaranya sebagai bahan acuan dan perbandingan.

\subsection{Implementasi Dynamic Walking pada Humanoid Robot Soccer [1]}

Pada penelitian ini dirancang sebuah robot pemain sepak bola dengan menggunakan metode dynamic walking. Metode dynamic walking adalah metode berjalan dimana robot berjalan secara tegap dan menyerupai manusia. Metode ini membuat robot dapat berjalan lebih cepat dibandingkan metode berjalan static walking karena dengan berjalan dengan postur tegap, robot akan memiliki langkah yang lebih lebar. Kendala yang muncul dalam pengujian adalah sampai saat ini belum ada rumus umum untuk membuat sebuah robot bisa berjalan dengan stabil menggunakan metode dynamic walking. Sehingga pengujian harus dilakukan secara trial and error pada robot. Pengujian secara trial and error jelas membutuhkan waktu yang cukup lama untuk mencapai tingkat kestabilan robot yang baik.

\subsection{Robot Humanoid Pemain Bola [2]}

Pada penelitian ini dirancang sebuah robot humanoid yang mempunyai 20 sendi dengan sensor CMUCam3 yang digunakan untuk sistem penglihatan robot. Sensor percepatan DE-ACCM3D yang digunakan untuk mengetahui kondisi robot ketika terjatuh. Otak dari robot menggunakan pengontrol mikro ATMEGA128 dan pengontrol servo SSC-32 untuk mengatur pergerakan motor servo. Keberhasilan robot humanoid pada saat berjalan lurus adalah $100 \%$ dengan waktu rata - rata pada saat menempuh jarak $100 \mathrm{~cm}$ adalah 112.8 detik, keberhasilan robot pada saat berjalan arah kanan sejauh $100 \mathrm{~cm}$ adalah $100 \%$ dengan waktu rata - rata 139.4 detik, keberhasilan robot pada saat berjalan arah kiri sejauh $100 \mathrm{~cm}$ adalah 90\% dengan waktu rata - rata 137.2 detik.

\section{Perancangan dan Penerapan}

Sebagaimana umumnya sebuah robot, sistemnya akan terdiri dari mekanik, perangkat keras dan perangkat lunak. Titik berat penelitian ini pada pengembangan dan evaluasi kinerja algoritma baru, meskipun demikian hal mekanik dan perangkat keras tetap akan dibahas secara ringkas untuk memberikan pemahaman yang lebih utuh.

\subsection{Gambaran Mekanik Robot}

Mekanik robot yang digunakan dalam penelitian ini merupakan mekanik yang sama dengan yang digunakan tim robot UKSW untuk bertanding dalam KRSBI 2013. Basisnya adalah robot humanoid dengan dimensi panjang tinggi $38 \mathrm{~cm}$, lebar $17 \mathrm{~cm}$, dan lebar tapak kaki masing - masing 6,5 cm, seperti yang terlihat pada Gambar 1 . 


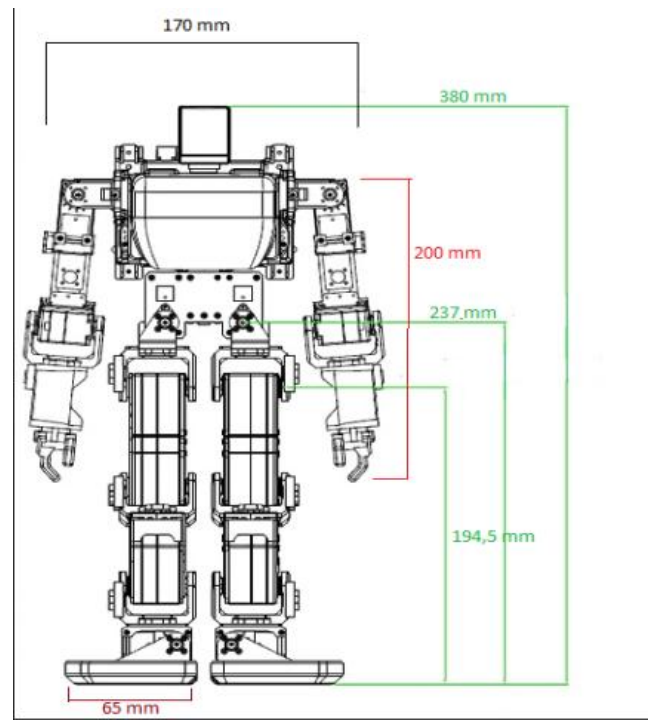

Gambar 1. Konstruksi dan dimensi robot humanoid yang digunakan [3]

Robot menggunakan perpaduan antara aluminium dan aklirik untuk bodinya. Perpaduan kedua bahan ini dimaksudkan agar robot memiliki bobot yang ringan sehingga dalam bergerak diperoleh kecepatan dan keseimbangan yang baik. Robot ini akan memiliki 16 degree of freedom, dengan rincian 5 di setiap kaki, dan 3 di setiap lengan. Motor servo yang dipilih adalah adalah yang memiliki torsi tinggi dengan gear berbahan metal dan yang mampu untuk mengembalikan nilai, seperti sudut, beban, torsi, dll. Ukuran telapak kaki menyesuaikan dengan tinggi robot agar mampu menyokong robot agar tetap stabil.

\subsection{Perangkat Keras Robot}

Sistem yang direalisasikan adalah sebuah sistem yang berfungsi untuk mengendalikan sebuah robot humanoid pemain sepakbola dalam menyelesaikan misi pertandingan pada KRSBI. Dalam KRSBI, robot harus dapat bergerak dengan cepat dan stabil agar dapat mendekati bola dan menendang bola ke arah gawang dengan cepat dan akurat. Oleh karena itu sistem didukung dengan sensor - sensor pergerakan seperti akselerometer dan giroskop untuk membantu robot dalam memulai pergerakan yang cepat, stabil, dan dapat bangun sendiri ketika robot dalam posisi jatuh. Gambar 2 memperlihatkan diagram blok sistem secara keseluruhan.

Sistem kontrol pada robot dibagi menjadi 2 bagian utama, yaitu kontrol aktuator robot dan kontrol utama. Kontrol aktuator robot dalam hal ini adalah servo controller seri RCB-4 untuk mengontrol sistem gerak robot yang terdiri dari motor - motor servo seri KRS-2552HV, dimana servo controller mendapat perintah gerakan yang sudah didefinisikan di kontrol utama. Sedangkan kontrol utama bertugas untuk melakukan sinkronisasi antara gerak robot dengan perintah yang telah diolah oleh mikrokontroler sehingga nantinya robot dapat melakukan tugas sesuai dengan perintah yang dikirim dari smartphone.

Robot memiliki 16 motor servo, dengan rincian 3 motor servo di setiap lengan dan 5 motor servo di setiap kaki. Dengan demikian robot akan memiliki 16 derajat kebebasan sehingga pergerakan robot akan mendekati pergerakan dari manusia. Untuk mengontrol 16 motor servo di bagian lengan dan kaki digunakan servo controller yang akan dibantu oleh sebuah giroskop dua-sumbu seri KRG-4 yang berfungsi sebagai sensor 
keseimbangan dan stabilitas robot saat bergerak dan akselerometer dua-sumbu seri RAS2 yang berfungsi sebagai sensor kemiringan untuk mengetahui ketika posisi robot miring atau posisi robot dalam keadaan jatuh.

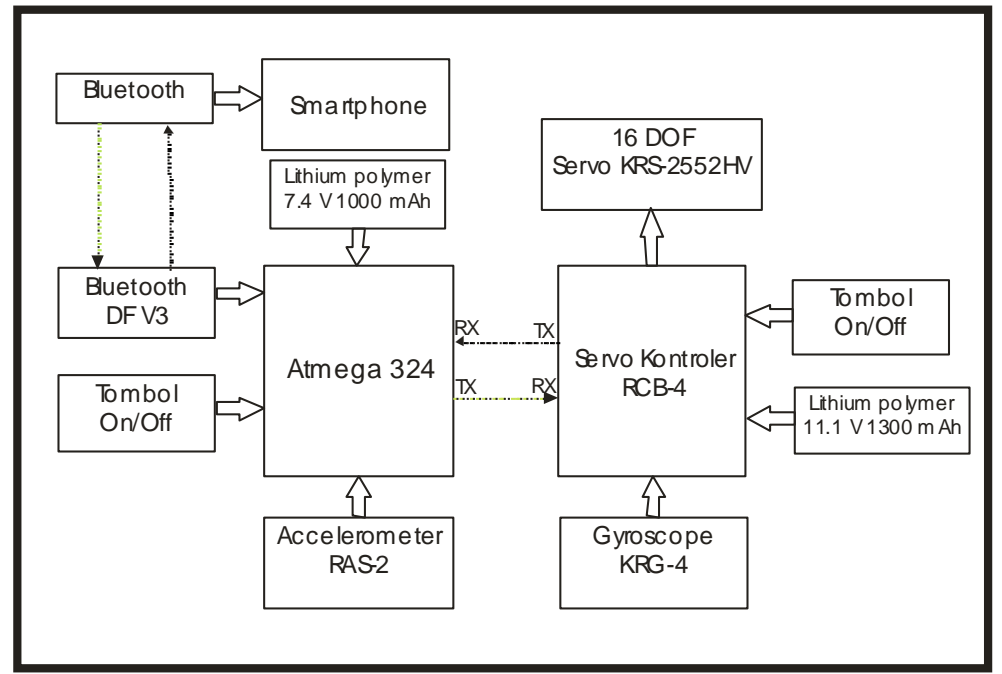

Gambar 2. Diagram blok perangkat keras robot humanoid pemain sepak bola

Kontrol utama pada robot terdiri dari sebuah smartphone untuk mengirimkan perintah gerakan robot dan sebuah mikrokontroler untuk menerjemahkan data menjadi rangkaian gerakan. Modul bluetooth digunakan untuk komunikasi secara serial antara smartphone dan mikrokontroler. Selain itu kontrol utama juga bertugas sebagai pengontrol servo controller. Smartphone pada tugas akhir ini digunakan sebagai sarana kendali jarak jauh untuk mengendalikan robot secara nirkabel. Smartphone yang digunakan adalah Samsung Galaxy S3 yang telah tertanam OS android di dalamnya. Aplikasi dibuat dengan Eclipse. Data yang dikirim dari smartphone android berupa paket data motion yang akan diterima oleh mikrokontroler. Pengiriman data dilakukan secara serial melalui perangkat bluetooth seri DF V3.

\subsection{Perangkat Lunak Pengendali Robot}

Pada bagian ini akan diberikan empat buah flowchart yang menggambarkan jalannya program saat robot bergerak. Setiap algoritma digambarkan dengan dua diagram alir yaitu diagram alir program pada mikrokontroler dan diagram alir program pada servo controller. Sedangkan flowchart ke - empat adalah algoritma baru saat robot menerima instruksi motion yang tidak berulang.

Algoritma pertama ini adalah algoritma yang digunakan robot humanoid dalam perlombaan KRSBI 2013. Algoritma yang digunakan masih sangat sederhana. Robot belum dapat melakukan motion cut dan belum dapat mengetahui posisi terakhir kaki robot. 

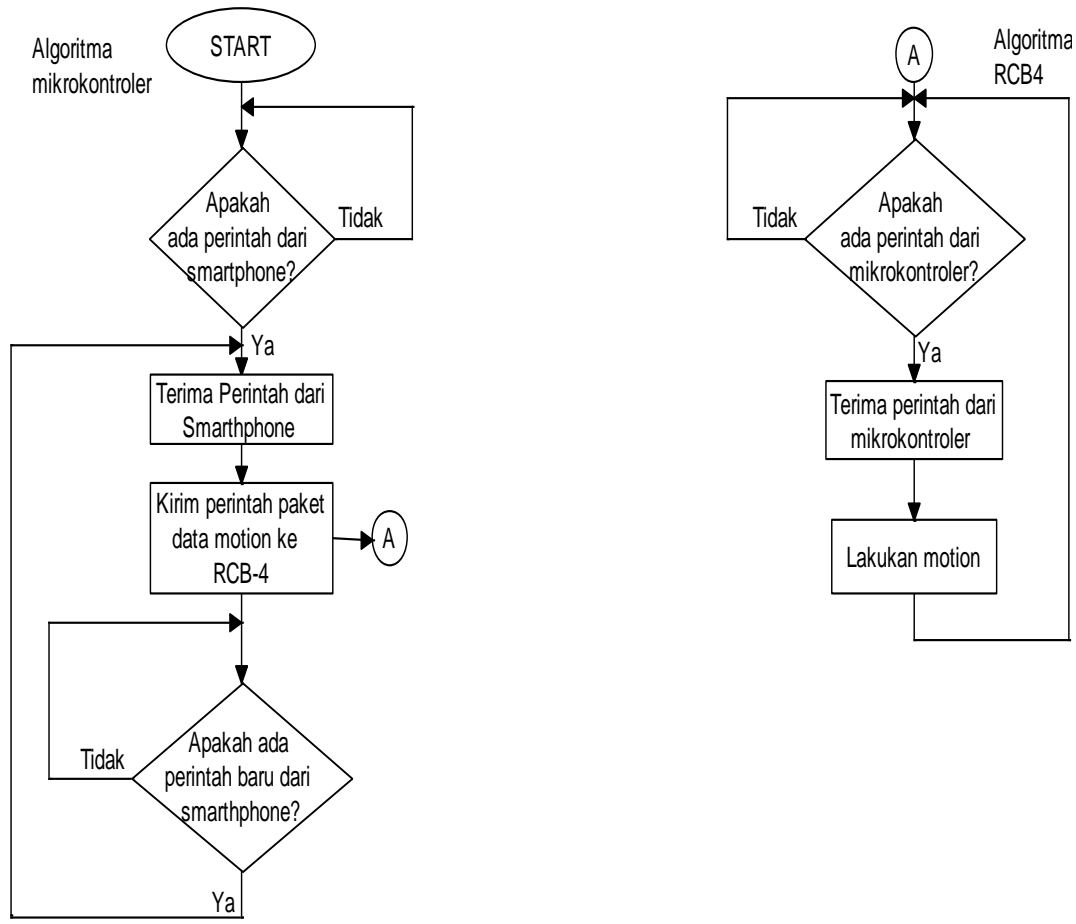

Gambar 3. Diagram alir algoritma pertama

Algoritma ke - dua adalah algoritma baru saat robot menerima instruksi motion berulang yang bergerak maju. Gambar 4 menunjukkan dua diagram alir sebagai gambaran algoritma ke - dua.

Algoritma ke - tiga adalah algoritma baru yang menunjukkan respon robot saat menerima instruksi motion berulang yang berupa gerakan geser. Gambar 5 menunjukkan dua diagram alir sebagai gambaran algoritma ke - tiga.

Algoritma ke - empat adalah algoritma baru yang menunjukkan respon robot saat menerima instruksi motion yang tidak berulang. Dua diagram alir sebagai gambaran algoritma ke - empat ditunjukkan oleh Gambar 6. 

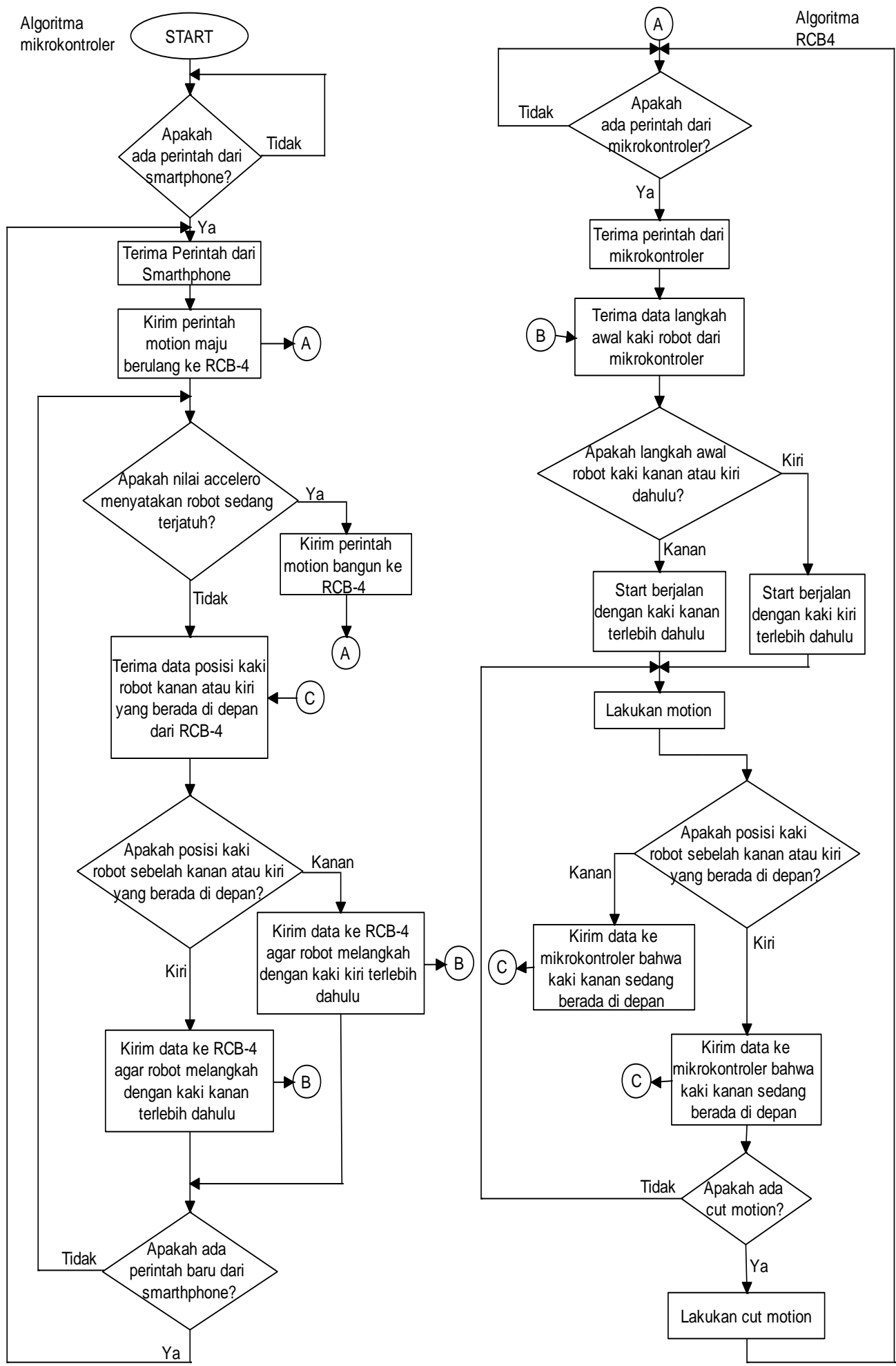

Gambar 4. Diagram alir algoritma ke - dua 

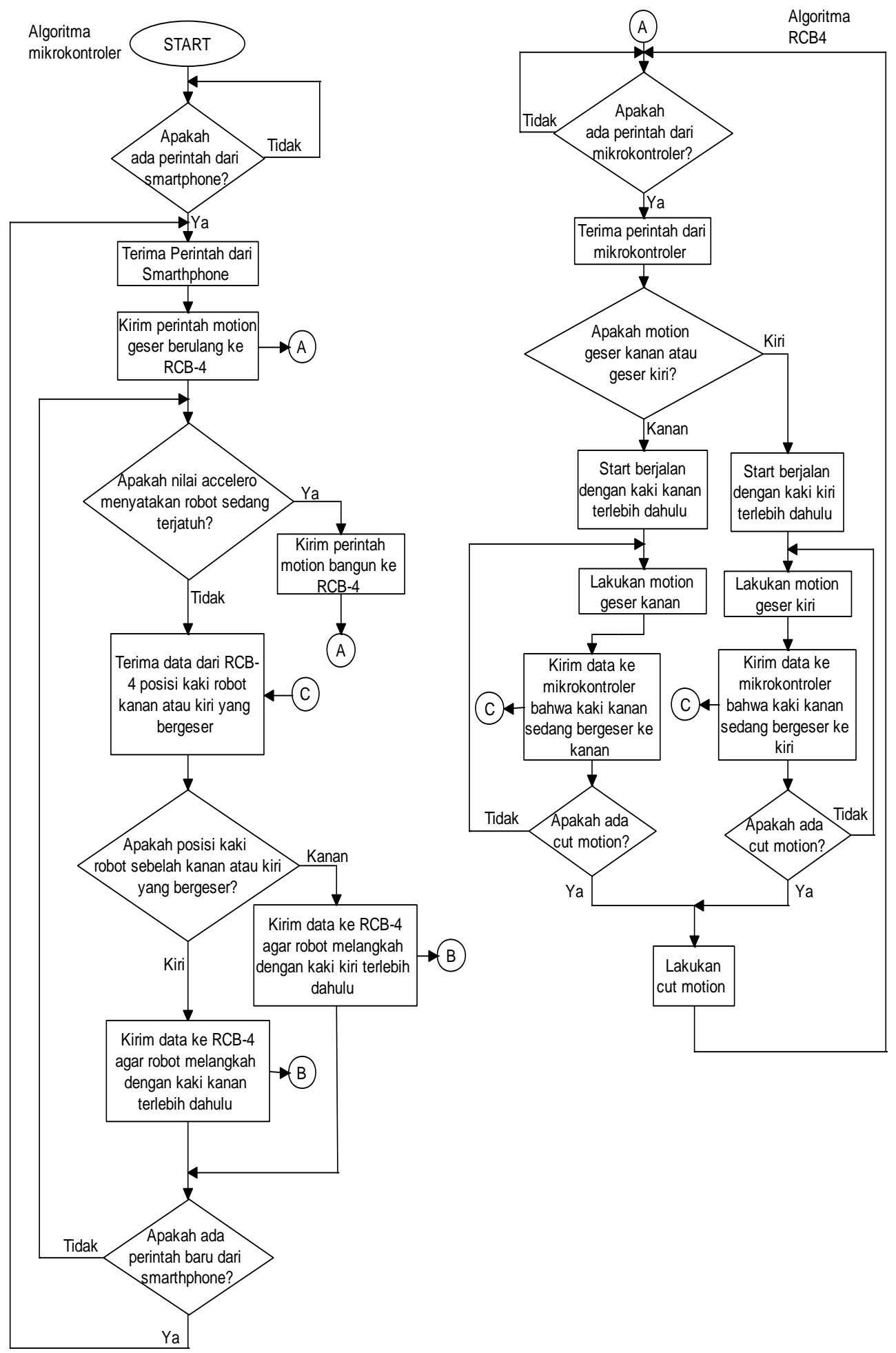

Gambar 5. Diagram alir algoritma ke - tiga 


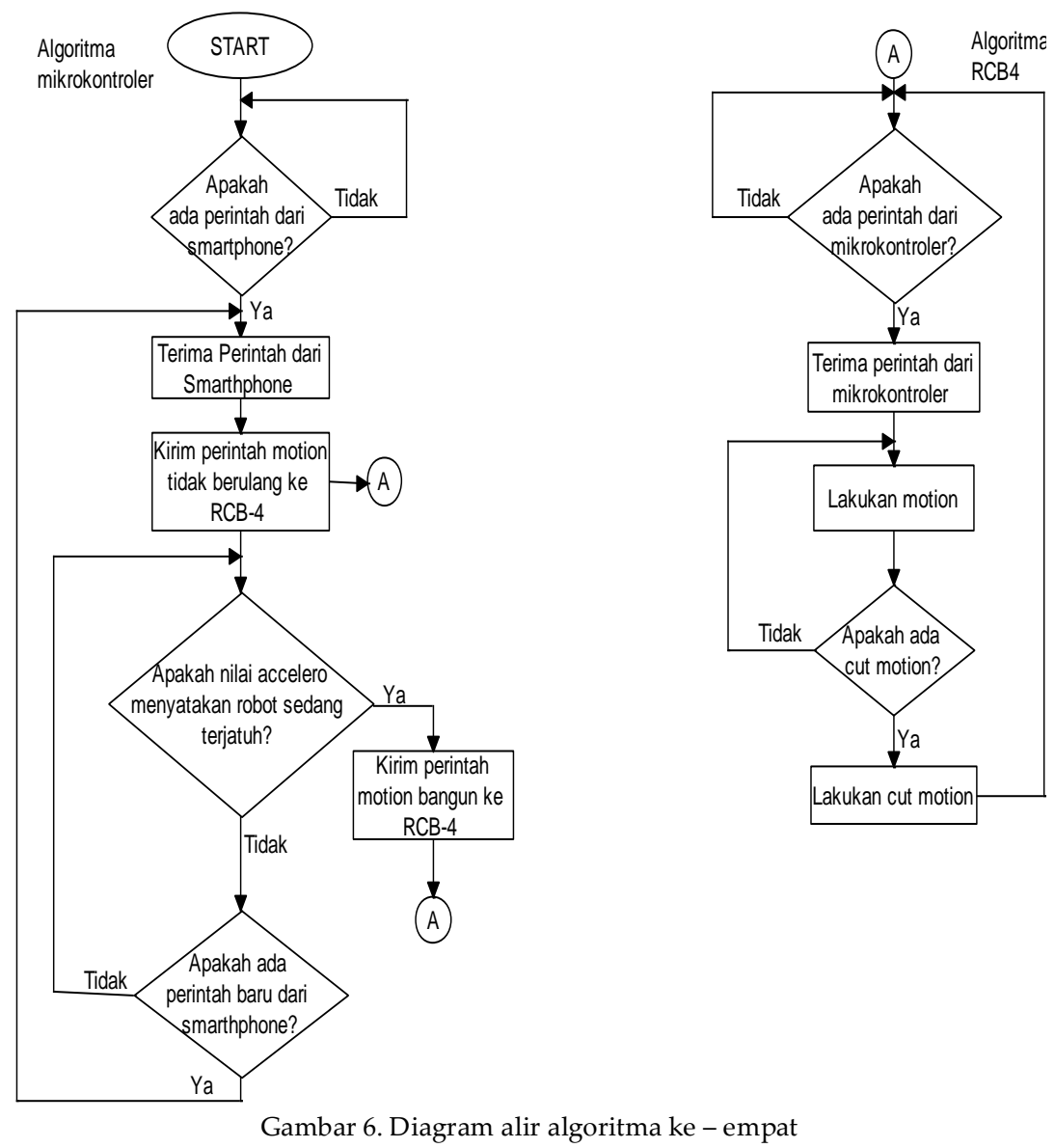

\section{Pengujian dan Pembahasan}

Evaluasi kinerja robot yang telah menggunakan algoritma pengendalian robot yang telah diperbaiki dilakukan melalui beberapa macam pengujian. Fokus pengujian adalah tentang kecepatan dan kestabilan gerak robot ketika dilakukan motion cut.

\subsection{Pengujian Kecepatan Gerak}

Pengujian kecepatan gerak dilakukan untuk gerakan maju lambat, maju cepat, geser kanan, geser kiri, putar kanan, dan putar kiri. Kecepatan rata - rata yang diperoleh dari hasil pengujian dapat dilihat pada Tabel 1.

Tabel 1. Kecepatan rata - rata robot untuk tiap jenis gerakan

\begin{tabular}{|c|c|}
\hline Jenis Gerakan & Kecepatan Rata - Rata \\
\hline Maju Lambat & $3,85 \mathrm{~cm} / \mathrm{s}$ \\
\hline Maju Cepat & $14,53 \mathrm{~cm} / \mathrm{s}$ \\
\hline Geser Kanan & $3,72 \mathrm{~cm} / \mathrm{s}$ \\
\hline Geser Kiri & $3,81 \mathrm{~cm} / \mathrm{s}$ \\
\hline Putar Kanan & $30,10^{\circ} / \mathrm{s}$ \\
\hline Putar Kiri & $23,86^{\circ} / \mathrm{s}$ \\
\hline
\end{tabular}

Kecepatan gerak robot ini sebenarnya juga dibatasi oleh spesifikasi motor servo yang digunakan. Apabila robot dipaksa bergerak dengan cepat dengan beban berat akan berakibat pada terbakarnya motor DC dan MOSFET yang ada dalam motor servo. 


\subsection{Pengujian Kestabilan}

Pengujian kestabilan dilakukan dengan cara memerintahkan robot untuk menendang, jatuh dari bangun, dan melakukan motion cut yang bervariasi. Untuk menyelesaikan gerakan tendang kanan dan kiri robot membutuhkan waktu rata - rata berturut - turut 2,39 detik dan 2,17 detik dari lima kali percobaan. Untuk menyelesaikan gerakan berdiri kembali dari jatuh depan dan belakang robot membutuhkan waktu rata - rata berturut turut 3,32 detik dan 3,70 detik dari lima kali percobaan.

Penulis membuat sebuah algoritma baru yang dapat membuat robot tetap stabil saat robot melakukan proses pergantian gerakan dari gerakan satu ke gerakan yang lain tanpa adanya waktu tunda pada program. Dengan tidak adanya waktu tunda dalam program, maka sangat besar kemungkinan robot tidak stabil dan terjatuh pada fase transisi pergantian gerakan. Algoritma yang dibuat oleh penulis dapat mengatasi kejadian tersebut dengan cara melakukan metode motion cut dengan pengecekan posisi kaki robot sehingga robot dapat mengetahui langkah kaki sebelumnya dan langkah kaki yang harus digerakan terlebih dahulu. Penulis juga memanfaatkan giroskop untuk mengatasi ketidakstabilan robot ketika dalam fase transisi pergantian gerakan tersebut.

Dari berbagai variasi perubahan gerakan, robot yang menggunakan algoritma pengendali lama hanya memiliki tingkat keberhasilan melakukan motion cut sebesar $41 \%$. Ketika robot menggunakan algoritma pengendali baru, tingkat keberhasilan menjadi $95 \%$.

Meskipun demikiran, algoritma baru masih memiliki kelemahan. Robot banyak mengalami kegagalan saat melakukan proses motion cut ketika robot bergerak maju kecil kemudian bergerak maju kurva baik kanan maupun kiri te. Hal ini terjadi karena ketika robot melakukan gerakan maju kecil, langkah yang dilakukan robot sangat pelan dengan langkah yang kecil, sehingga ketika robot dipaksa untuk mengganti gerakan menjadi maju kurva, sangat sulit untuk membuat robot tetap stabil dikarenakan perubahan kecepatan robot yang sangat cepat. Gerakan maju kurva sendiri yang dibuat penulis belum sempurna sebab penulis mengalami kesulitan mengatur kestabilan dari gerakan tersebut. Ketika robot bergerak maju kurva kanan, robot pasti akan lebih condong ke kanan dan membuat titik berat berada lebih ke bagian kanan sehingga sangat besar kemungkinan robot untuk jatuh ketika melakukan proses motion cut, sama halnya ketika robot melakukan gerakan maju kurva kiri.

Kegagalan motion cut yang dilakukan robot juga banyak terjadi ketika robot melakukan proses motion cut di antara gerakan maju kecil ke geser kecil baik kanan maupun kiri. Kegagalan terjadi dikarenakan adanya ketidaksinkronan antara pengiriman data dari smartphone dan waktu penerimaan data balikan dari RCB-4 yang dilakukan oleh mikrokontroler. Ketika smartphone memberi perintah kepada mikrokontroler untuk melakukan proses motion cut, mikrokontroler belum siap karena mikrokontroler belum menerima data balikan dari RCB-4 tentang posisi kaki robot sehingga membuat robot sering kali salah melangkah dan terjatuh.

\section{Kesimpulan}

Berdasarkan perancangan, perealisasian dan pengujian dapat ditarik kesimpulan sebagai berikut :

1. Mekanik robot dan perangkat keras dapat bekerja baik dalam mendukung penerapan algoritma pengendali robot. 
2. Rata - rata persentase keberhasilan untuk melakukan motion cut algoritma lama $41 \%$ dan sedangkan algoritma baru mencapai 95\%, dengan demikian algoritma baru memiliki kinerja lebih baik dibanding algoritma lama.

3. Robot dapat menjaga kestabilan tubuhnya dalam berbagai gerakan, termasuk ketika menendang dan terjatuh.

\section{Daftar Pustaka}

[1] D. Suryawan,"Implementasi Dynamic Walking pada Humanoid Robot Soccer", Prosiding ISRSC, 2013.

[2] Muliady,"Robot Humanoid Pemain Bola", Prosiding ISRSC, 2013.

[3] RoboTron, "Robot Humanoid", [online], http://robotronix1.blogspot.com/2012/09/ robot-humanoid.html, diakses tanggal 12 September 2013. 